\title{
A PRODUÇÃO EDITORIAL DE REVISTAS CIENTÍ́FICAS POR MEIO DO OJS NA PUCPR: Desafios iniciais da utilização do sistema e da gestão de periódicos
}

\author{
Paula Lorena Silva Melo \\ Pontifícia Universidade Católica do Paraná \\ paula.lorena@grupomarista.org.br \\ Marcelo Manduca \\ Pontifícia Universidade Católica do Paraná \\ manduca.marcelo@grupomarista.org.br \\ Elisama Nunes dos Santos \\ Pontifícia Universidade Católica do Paraná \\ elisama.santos@grupomarista.org.br
}

\begin{abstract}
Resumo
O presente artigo tem como objetivo apresentar a situação da gestão da produção editorial de periódicos científicos da Pontifícia Universidade Católica do Paraná (PUCPR) apoiados pela Editora PUCPRESS, mostrando as principais vantagens e desafios percebidos ao longo do uso do Open Journal Systems (OJS/ SEER). Dentre as vantagens, incluem-se a maior transparência do processo editorial e a maior visibilidade dos artigos por meio de metadados bem estruturados. Entre os desafios, elencam-se aqueles relacionados à experiência do usuário e à sazonalidade das operações, bem como particularidades da produção editorial que o sistema não comporta com grau de controle suficiente. Para lidar com os desafios, foram criadas estratégias que envolvem treinamentos específicos e tutoriais para os usuários do sistema, em especial editores e equipes dos periódicos.
\end{abstract}

Palavras-Chave

Periódicos científicos. Produção editorial. Open Journal Systems. Gestão editorial.

\section{INTRODUÇÃO}

A produção editorial de revistas científicas é uma sequência de etapas que, em suma, abrange quatro grandes processos: submissão, avaliação, edição e publicação (WILLINSKY, 2005). Aqui, contaremos ainda com uma quinta etapa, a de pós-publicação, que será descrita adiante. Para organizar essas etapas, é aconselhável a utilização de sistemas de publicação, especialmente para revistas eletrônicas, que garantam a transparência do processo, reduzam erros e possibilitem um maior controle do fluxo de produção editorial.

A escolha de usar esses sistemas, no entanto, não é livre de desafios em todas as suas etapas, da implantação ao uso propriamente dito. Por contar com diversos atores em cada parte do processo, amplia-se a necessidade de treinamento e monitoramento de cada etapa, especialmente durante os primeiros períodos de utilização. Conforme os usuários atingem maturidade de uso do sistema, alguns desses desafios são solucionados e 
outros, minimizados. O ideal é que o usuário atinja autonomia em relação ao sistema para poder operá-lo de forma independente e com capacidade de resolver eventuais problemas decorrentes do uso.

O objetivo do presente artigo é apresentar a situação da gestão da produção editorial, especialmente das etapas de avaliação, edição e publicação, das revistas da Pontifícia Universidade Católica do Paraná (PUCPR) apoiadas pela equipe de periódicos da Editora PUCPRESS ${ }^{1}$. No que diz respeito ao sistema em uso, o Open Journal System (OJS), salientamse aqui as vantagens do sistema, os desafios de sua utilização e algumas estratégias usadas para minimizar o impacto desses desafios no gerenciamento dos periódicos.

\section{A PRODUÇÃO EDITORIAL E SEU ACOMPANHAMENTO}

A PUCPR conta atualmente uma equipe de revistas coordenada pela Editora PUCPRESS, que presta apoio às revistas da instituição no papel de incubadora. É função dessa equipe acompanhar o início das revistas interessadas em utilizar o sistema OJS, ajudar a sua configuração inicial dentro do portal de periódicos da instituição, auxiliar a obtenção dos registros aplicáveis, treinar as equipes de cada periódico na utilização do sistema e prestar auxílio pontual referente ao sistema, processo editorial e qualidade da publicação

Cada revista conta com uma equipe própria, cuja composição varia de periódico para periódico, chefiada pelo editor da publicação. Após o treinamento inicial no sistema, as etapas de submissão e avaliação são de responsabilidade integral dessa equipe. As etapas de edição, publicação e pós-publicação podem ser feitas pela Editora PUCPRESS ou por terceiros contratados pela equipe de cada periódico, como pode-se ver no Quadro 1.

Quadro 1 - o processo editorial e seus responsáveis por etapas

\begin{tabular}{|l|l|}
\hline Etapa do processo editorial & Responsáveis \\
\hline Submissão & Equipe da revista \\
\hline Avaliação & Equipe da revista \\
\hline $\begin{array}{l}\text { Edição (Preparação de texto e } \\
\text { Edição de layout) }\end{array}$ & $\begin{array}{l}\text { Equipe PUCPRESS } \\
\text { Terceiros (contratados pela equipe da revista) }\end{array}$ \\
\hline Edição de layout) & $\begin{array}{l}\text { Equipe PUCPRESS } \\
\text { Terceiros (contratados pela equipe da revista) }\end{array}$ \\
\hline Pós-publicação & $\begin{array}{l}\text { Equipe PUCPRESS } \\
\text { Terceiros (contratados pela equipe da revista) }\end{array}$ \\
\hline
\end{tabular}

Fonte: Elaborado pelos autores (2018)

O acompanhamento da produção editorial começa na submissão, pelos autores, do artigo a um periódico ativo. A equipe do periódico confere as submissões para que possam seguir à etapa seguinte e, depois disso, o artigo é designado a no mínimo dois pareceristas para a etapa de avaliação. Nas revistas apoiadas pela PUCPRESS, o sistema de avaliação é o duplo-cego por pares (peer review). Os pareceristas são designados pelo(s) editor(es) da revista com base em um banco de pareceristas cadastrados, considerando-se suas áreas de atuação.

Se a avaliação dos pareceristas for

\footnotetext{
${ }^{1}$ Neste artigo, designaremos como "equipe PUCPRESS" a equipe de revistas que exerce o papel de incubadora e apoio às publicações e como "equipe da revista" ou "equipe do periódico" a equipe de cada periódico, que se reporta diretamente ao editor da revista.
} 
positiva, o artigo é aprovado e segue, após as devidas correções (se aplicáveis) para a etapa de edição. Essa etapa envolve dois grandes processos: preparação (ou edição) de texto e edição de layout.

A preparação de texto envolve, nas revistas apoiadas pela PUCPRESS, a normalização, revisão ortográfica, gramatical e sintática, a conferência de referências e uma nova verificação de similaridades. Itens em desacordo encontrados nessa etapa são validados, a depender do tipo de disparidade, com o autor ou com o autor e o editor. Sem que esses itens sejam solucionados, o artigo não prossegue para a segunda parte da etapa.

A parte de edição de layout envolve a adequação do artigo ao projeto gráfico da revista e uma última conferência para identificar eventuais não conformidades da parte visual.

Nas duas partes da etapa de edição, não há alterações de conteúdo, pois entende- se que a integridade dos pareceres da etapa de avaliação pode ser prejudicada se esse tipo de alteração acontecer.

Após a etapa de edição, o artigo segue para a publicação, que envolve o upload do arquivo final no sistema que servirá de repositório, a atualização e conferência de todos os metadados aplicáveis e a disponibilização do artigo em sua forma online.

Por fim, há ainda uma etapa de póspublicação. Nesta etapa, são registrados então os Digital Object Identifier (DOI) dos artigos e do número da revista e notificam-se os leitores da revista a respeito da publicação do novo número. Também é nessa etapa que há o direcionamento do arquivo para que seja gerado o XML ou outros formatos de publicação, em especial os requisitados por indexadores.

As etapas são executadas sequencialmente, como apresentado na Figura 1.

Figura 1 - Fluxograma simplificado das etapas de produção de um artigo aprovado

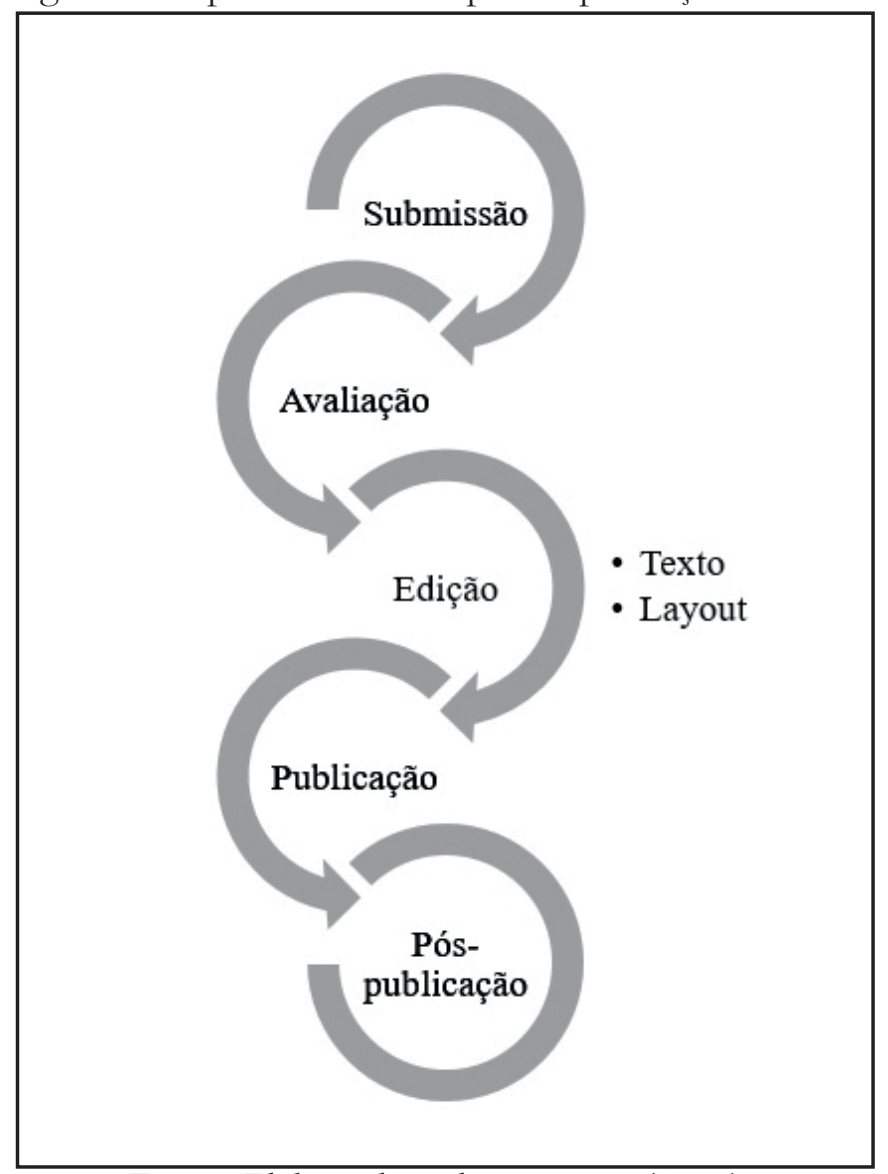

Fonte: Elaborado pelos autores (2019) 


\section{A UTILIZAÇÃO DO OPEN JOURNAL SYSTEMS (OJS)}

O sistema de gestão de produção editorial de periódicos atualmente em uso na PUCPR é o OJS. De acordo com Alperin, Stranack e Garnett (2016, p. 58, tradução nossa):

[...] o OJS é uma plataforma profissional de publicação de periódicos que é fácil de baixar, instalar e operar com requisitos mínimos de sistema. O OJS permite submissões on-line, avaliação por pares, edição de texto e de layout e publicação. Ele também proporciona conexões com indexadores (p.e., PubMed, DOAJ), identificadores digitais de conteúdo (p.e., CrossRef, ORCID) e serviços de preservação (p.e., LOCKSS, Portico).

O OJS, também chamado de SEER, Sistema de Editoração Eletrônica de Revistas, em sua versão customizada especialmente para o Brasil (INSTITUTO BRASILEIRO DE INFORMAÇÃO EM CIÊNCIA E TECNOLOGIA, 2018), é desenvolvido pelo Public Knowledge Project (PKP), "uma iniciativa multiuniversidade que desenvolve software open source (gratuito) e conduz pesquisas para melhorar a qualidade e o alcance das publicações acadêmicas" (PUBLIC KNOWLEDGE PROJECT, 2014, tradução e grifos nossos). O OJS é, portanto, open source e gratuito, alinhado com a ideia do projeto.

A escolha por este sistema e sua implantação levaram em conta esses aspectos, além do fato de ele possibilitar a criação de um portal de periódicos e ter uma interface já em uso por vários periódicos de diversas áreas no Brasil e no exterior (KEVIN, 2015), o que se esperava que fosse minimizar alguns problemas de adaptação ao sistema.

$\mathrm{Na}$ PUCPR, o sistema foi implantado durante o ano de 2016 e entrou em uso em 2017. Durante o primeiro ano de utilização, foram migrados os processos editoriais, anteriormente em um sistema próprio, e as edições anteriores das revistas ativas e inativas mapeadas pela Editora PUCPRESS. Também foram ministrados cursos de treinamento para as equipes dos periódicos, incluindo seus editores.

A utilização do sistema OJS traz diferenças em relação ao sistema anteriormente em uso, por mapear mais etapas e fornecer uma melhor visibilidade do conteúdo em andamento e publicado. Isso deu vez a uma série de vantagens, mas também a alguns desafios, como apresentaremos a seguir. As informações descritas nessa seção foram obtidas através de feedbacks voluntários dos usuários do sistema e de percepções da equipe responsável pelo auxílio e treinamento desses usuários.

\subsection{Vantagens}

Uma das principais vantagens do OJS apontadas pelos editores e equipes dos periódicos é a transparência do processo editorial. Segundo os editores, o acompanhamento da submissão dos artigos é mais simples, bem como a verificação das etapas já concluídas. Também foram informadas por eles a facilidade de gerenciar os aceites e recusas e a diminuição de problemas de prazo.

As equipes das revistas indicam que a comunicação com os autores ficou mais fácil e a observação dos prazos dessa comunicação também. Além disso, o versionamento de arquivos é possível e mantém-se um histórico que pode ser consultado no caso de dúvidas.

Em consonância com Ferreira e Caregnato (2008), a disponibilização dos metadados de forma organizada também foi indicada como um ponto de vantagem, pois deixa os artigos mais fáceis de serem encontrados e acessados.

Além desses pontos, a equipe PUCPRESS identificou que o tempo das etapas de edição e publicação foi otimizado em relação ao que ocorria no sistema anterior, por conta de fatores como facilidade de comunicação com os autores, maior controle das respostas de cada artigo de um periódico, recuperação de 
metadados a partir dos cadastros no sistema e simplicidade do sistema para envio das versões finais dos artigos e atualização de metadados.

\subsection{Desafios}

Um dos principais desafios da utilização do OJS tem sido a atualização e treinamento dos usuários. Com a instalação do novo sistema, era esperado um período de adaptação dos usuários, em especial aqueles que não fazem uso da ferramenta diariamente. Além do treinamento inicial, portanto, percebeu-se que era necessário rever algumas instâncias da parte operacional do sistema periodicamente, pois foram computadas como aquelas a respeito das quais os editores e suas equipes mais tinham questionamentos.

É necessário salientar que a maioria das dúvidas e dificuldades de processo verificadas pelos usuários têm a ver com a interface entre o OJS e outros sistemas, como provedores de e-mail, ou com o uso propriamente dito, sem que sejam falhas do sistema em si. Como uma das responsáveis pelo sistema e com mais de um periódico sob seu monitoramento, a equipe PUCPRESS recebe e soluciona vários desses questionamentos. Para esclarecer, elaboraremos a respeito de alguns deles a seguir.

\subsubsection{Designação de pareceristas}

O primeiro questionamento diz respeito à designação de pareceristas. Essa etapa apresenta frequentemente duas dificuldades: cadastro de pareceristas e comunicação da avaliação. A maioria das revistas científicas opera com um banco de pareceristas próprio, muitos dos quais fazem pareceres para mais de uma revista a depender de sua área de atuação. Como anteriormente essa parte do processo não era contemplada via sistema, ainda há ruídos na hora de cadastrar novos pareceristas e habituá-los ao novo sistema.

Idealmente, o cadastro do parecerista deve ser feito pelo próprio parecerista. Em casos como o que temos em mãos, em que houve uma migração de um sistema anterior para o OJS, considerou-se mais conveniente que os próprios editores cadastrassem os pareceristas e/ou designassem como parecerista aqueles que já tinham cadastro dentro do sistema. Isso aconteceu para evitar que nomes se perdessem e que a produção das revistas atrasasse, pois toda essa operação aconteceu com várias revistas ainda em andamento.

Quando o cadastro de um parecerista é feito pelo editor, há necessidade de troca da senha de acesso no primeiro acesso do parecerista, por motivos de segurança. Essa indicação é feita no e-mail que se envia ao avaliador quando se solicita a avaliação. Entretanto, para pareceristas não habituados ao sistema, é necessário que o editor entre em contato e instrua-os mais claramente a respeito da ferramenta, o que gera algumas dúvidas da parte do editor.

Além disso, enfrenta-se a dificuldade de se comunicar a avaliação. Alguns provedores de e-mail, especialmente institucionais, não compreendem o e-mail de notificação do OJS como mensagem normal e acabam desviando-o para a caixa de spam, que raramente é verificada. Assim, fica impossível saber se o avaliador sequer recebeu a mensagem, para que se possa decidir se ele deve ou não ser mantido na avaliação daquele artigo, o que pode atrasar o processo.

Para diminuir esses problemas, a instrução que vem sendo transmitida é de que os editores entrem em contato com os pareceristas previamente, para consultar se eles estão familiarizados com o OJS e se têm disponibilidade de fazer uma avaliação. Assim, o parecerista pode se colocar de sobreaviso, evitando situações como a descrita acima.

\subsubsection{Instrução de autores}

De forma similar ao que ocorre com os pareceristas, que às vezes precisam ser instruídos, também os autores requerem, por vezes, instruções mais pontuais a respeito de alguns itens. É interessante salientar que 
a mensagem enviada ao autor ao final das etapas de avaliação e edição de texto tende a ser clara quando há uma familiaridade do autor a sistemas em geral e ao OJS em particular. Quando isso não acontece, o autor enfrenta dificuldades e desenvolve certa resistência ao sistema.

Dentre as dúvidas de autores, as mais comuns dizem respeito a erros de envio de arquivos, pois não está claro que, se foi enviado um arquivo errado, este pode ser substituído no mesmo local do envio do primeiro arquivo, e à conclusão, no sistema, da tarefa de revisão da edição de texto. Boa parte dos autores não conclui a tarefa no sistema, gerando um momento de retrabalho em que essa conclusão tem que ser exigida e, na maioria dos casos, explicada. No geral, não tivemos reincidência de autores nessas dúvidas, embora elas surjam periodicamente devido à quantidade de autores com que se lida durante a produção de uma revista.

\subsubsection{Designação de versão}

Periodicamente, surgem dúvidas a respeito da designação de versões de um arquivo no sistema, seja para o parecer cego, seja para a etapa de edição. No geral, essas dúvidas são pontuais e acontecem em revistas com maior espaçamento entre as periodicidades. Conforme pudemos observar, na ampla maioria das vezes trata-se mais de uma confirmação do processo do que de uma dúvida propriamente dita.

Ao final da etapa de avaliação, porém, é comum que a versão não seja designada para edição, especialmente nos casos em que esta etapa é feita por pessoas fora da equipe imediata da revista. Esta também se torna, assim, uma operação de interface, ficando mais sujeita a riscos, pois a responsabilidade das etapas seguintes não é da mesma pessoa que coordenou as anteriores. Assim, o desconhecimento do operacional da etapa seguinte parece dificultar a internalização da rotina dos processos de designação presentes na etapa anterior.

\subsubsection{Acompanhamento de produção editorial na fase de edição}

O sistema não contempla, de forma satisfatória, a fase de edição de layout do processo editorial para as revistas em pauta. Entendemos que há variações nesse item a depender do modo como é feita a edição de layout, então salientamos que o percebido surgiu durante a edição de layout de periódicos que são diagramados em programas como o Adobe InDesign.

Apesar de haver um local designado para a edição de layout, não há uma tríade de passos como a que se apresenta na parte de edição de texto. O layout, uma vez colocado na sua etapa, fica então disponível simultaneamente para o editor, o autor e a equipe de edição.

$\mathrm{Em}$ artigos cuja edição de layout contempla transposição de um sistema a outro, é comum que a transposição de alguns itens falhe - sobrescritos que se tornam texto normal, fontes que não são alteradas, itálicos que precisam ser inseridos manualmente. Assim, o padrão de trabalho indica que seja feita uma conferência desse layout, bem como todas as correções aplicáveis, anteriormente à disponibilização para o autor e o editor. Devido ao modo como o sistema mostra essa etapa, obrigatoriamente essas primeiras correções ficam fora do sistema. Para evitar essa situação, houve uma tentativa de contornar essa particularidade por dentro do sistema, mas ela não se mostrou eficaz.

Durante alguns meses de uso do sistema, foi feito um teste em que o layout era disponibilizado em primeira versão para os autores e editores. A ideia era que este seria um modo de manter o histórico das provas e evitar versionamento incorreto dos arquivos. Antes que as primeiras correções, feitas pela equipe de edição de texto e layout, fossem finalizadas, porém, havia comentários dos autores e editores redundantes àqueles já mapeados. Isso causou retrabalho, pois a equipe responsável por essa 
primeira verificação precisou conferir um a um os comentários, sendo que estes já estavam em processo de alteração pelos editores de layout. Além disso, foi necessário reassegurar os autores, conforme os questionamentos chegavam, de que aquelas ocorrências eram comuns na transposição de arquivos de um formato a outro e estavam sendo tratadas, como de costume.

Tendo em vista o trabalho que essa situação acarretou para os envolvidos, foi necessário desenvolver um controle paralelo ao OJS no que diz respeito a essas etapas citando aqui, especialmente, casos como o da Editora PUCPRESS, que trata da edição de texto e layout de mais de uma revista com periodicidades próximas ou coincidentes a fim de que não fossem gerados erros nesta parte do procedimento.

\subsubsection{Pós-publicação e plugins}

O OJS oferece, além do acompanhamento da publicação, todo um sistema de plugins e recursos que cuida de algumas etapas de pós-publicação. Desde atribuição automática de DOIs a cadastro automático destes no Crossref, bem como criação de XML, entre outros, são diversas as ferramentas que auxiliam na indexação e registro dos artigos publicados.

A utilização dessas ferramentas, porém, teve percalços que não foram totalmente solucionados ainda. Primeiramente, vários dos plugins, quando habilitados, disparam alertas nas equipes que cuidam da manutenção do servidor em que o OJS está hospedado. Esses alertas não podem ser desativados, por questão de segurança, então os plugins não funcionam em sua totalidade.

Além disso, observou-se, no início, que o registro automático do DOI não gerava relatórios, via e-mail, de conclusão e sucesso ou falha, além de ser um método mais demorado, em seu processamento, que o download do XML dos metadados e inserção direta via Crossref. Isso gera uma necessidade maior de acompanhamento, por um período maior de tempo, o que se torna impraticável em situações como a que apresentamos aqui, em que as revistas em questão têm seus DOIs cadastrados exclusivamente pela equipe PUCPRESS, mantenedora do cadastro no Crossref.

Também a atribuição automática de DOIs tem funcionado parcialmente, em algumas revistas. Outras, por serem indexadas ou seguirem o padrão SciELO, ou mesmo terem padrões próprios de atribuição de DOI, continuam com atribuição manual, com conferência também manual. Para essas revistas, o registro do DOI via Crossref é mais aconselhável, pois eventuais erros de digitação ou atribuição de DOI podem ser conferidos no momento da submissão ao Crossref.

Tendo em vista esses itens, o acompanhamento da pós-publicação (notificação de usuários, registro do DOI e envio para geração de XML) continua sendo feito por controle externo ao sistema. Vale ressaltar que, anteriormente ao OJS, essa parte também era controlada externamente ao sistema em vigor.

\section{ENFRENTANDO OS DESAFIOS}

$\mathrm{Na}$ adoção do novo sistema, esperava-se de fato que se apresentassem desafios, em graus variados de complexidade. Acompanhando os editores e suas equipes, assim como outros usuários, nesse período de ajuste ao OJS, pudemos perceber que muitas das dúvidas provêm do fator inexperiência do usuário com o sistema específico ou, em alguns momentos, com sistemas em geral, para o que a principal metodologia de solução é o treinamento, aliado ao uso. Esse desafio já havia sido resumido por Eluan (2009, p. 86) em sua dissertação: "a ferramenta pode trazer agilidade no processo editorial, porém, isso não quer dizer que a mesma não precise de treinamento para o uso de suas funcionalidades".

O esperado é que, com treinamento contínuo e com o uso, a experiência dos 
usuários leve à eventual autonomia em relação ao sistema. É também esperado, entretanto, que esse desfecho aconteça em tempos variados para equipes diferentes e usuários com atribuições e tempo de uso do sistema diferentes, o que torna a tarefa de treinar os usuários do sistema mais particionada, pois há várias necessidades e níveis diferentes de experiência em questão.

O quadro agrava-se quando se leva em consideração que o uso feito por parte dos usuários não é contínuo e diário, preferindose trabalhar em "bateladas" de artigos. A escolha por essa metodologia de trabalho não será discutida aqui, mas, pelo informado pelos usuários, parece ser uma questão de facilidade de organizar o tempo desse modo.

Quando o usuário fica um tempo sem entrar em contato com algumas funcionalidades do sistema, é esperado que parte dos detalhes do uso sejam esquecidos ou confundidos. Essa sazonalidade era prevista, mas, segundo a percepção da equipe PUCPRESS, ainda assim influencia bastante na resolução dos desafios.

Para lidar com os questionamentos e desafios originários da falta de experiência do usuário e da sazonalidade de uso de algumas funções, a equipe PUCPRESS disponibiliza tempo para treinamento e solução de dúvidas. Além disso, são montados tutoriais específicos para etapas que geram mais dificuldades, a fim de reforçar algumas das práticas remotamente, sem que seja necessário treinamento presencial.

A equipe PUCPRESS, na construção desses tutoriais e na resolução de dúvidas do usuário, consulta os fóruns do Instituto Brasileiro de Informação em Ciência e Tecnologia (Ibict) e do PKP referentes ao OJS, além de fazer uso da própria experiência com o sistema. Entretanto, percebeu-se que muitos dos problemas apresentados nesses fóruns dizem respeito a atividades de desenvolvimento de sistema, servidor ou plugins, bem como questões sobre falhas no programa. Os tutoriais disponíveis online tendem a ser bastante abrangentes, o que se verificou, por experiência, que funciona bem para os treinamentos iniciais, mas é ineficiente na solução de dúvidas pontuais específicas de cada usuário.

Foi por isso que se preferiu a criação de manuais passo a passo de etapas e funções específicas, voltadas para os conjuntos de questionamentos e desafios mais enfrentados pelos editores e suas equipes. A ideia é que o material de consulta, visual e pontual, facilite a construção de autonomia do usuário sem onerar o tempo disponível para uso do sistema, evitando assim que o tempo de produção dos periódicos aumente. Além disso, periodicamente são realinhados os processos editoriais dentro do OJS com os editores, para garantir o bom funcionamento do processo.

Para lidar com os pontos de desafio que partem do que o sistema não contempla (itens 3.2.4 e 3.2.5), foi encorajada a criação de um controle paralelo que prevê essas etapas e é compartilhado por aqueles que trabalham nelas. Esse controle se fez ainda mais necessário tendo em vista que a Editora PUCPRESS apoia a gestão editorial de mais de um periódico.

O formato escolhido para essa ferramenta de controle foi de planilha Excel, pois o software é de uso corrente na editora e acessível a todos os envolvidos nas etapas mapeadas paralelamente ao OJS.

A planilha conta com todas as edições de uma revista em produção durante um ano, suas periodicidades, todos os artigos constantes de cada edição e todas as etapas de edição de cada artigo. É de preenchimento manual e mapeia todos os procedimentos que são responsabilidade da Editora PUCPRESS para as revistas que recebem esse apoio direto — a saber: edição, publicação e pós-publicação. A planilha conta com as datas de execução de cada item e células para identificar o status de eventuais pontos de atenção, como a presença de partes específicas do texto, a conferência de referências e todas as etapas da edição de layout. Ter esses itens à mão auxilia a equipe PUCPRESS a acompanhar o processo para as revistas apoiadas sem que seja necessário gerar relatórios diários a partir do OJS. 
Esse controle também auxilia no apoio aos editores dos periódicos, pois serve como retrato dos tempos de processo para cada uma das etapas e permite a visualização detalhada dos tempos de mais de um artigo ao mesmo tempo. Também se identificou que ela diminui a possibilidade de serem ignoradas falhas provenientes de uso incorreto do sistema, especialmente levando em conta que a utilização do sistema dentro da PUCPR ainda é recente.

O Quadro 2 resume os desafios e as estratégias usadas para contornar ou resolvê-los.

Quadro 2 - Desafios da gestão de periódicos através do OJS, seu tipo e estratégias de solução

\begin{tabular}{|c|c|c|}
\hline Desafio & Tipo & Estratégia \\
\hline Designação de pareceristas & $\begin{array}{l}\text { - Experiência do usuário } \\
\text { - Sazonalidade da } \\
\text { operação }\end{array}$ & $\begin{array}{ll}\text { - } & \text { Uso } \\
\text { - } & \text { Tutoriais }\end{array}$ \\
\hline Instrução de autores & Experiência do usuário & $\begin{array}{l}\text { Comunicação mais clara na } \\
\text { página da revista e nos e-mails }\end{array}$ \\
\hline Designação de versão & $\begin{array}{l}\text { - Experiência do usuário } \\
\text { - Sazonalidade da } \\
\text { operação }\end{array}$ & $\begin{array}{l}\text { - Uso } \\
\text { - Tutoriais }\end{array}$ \\
\hline $\begin{array}{l}\text { Acompanhamento da fase de } \\
\text { edição }\end{array}$ & $\begin{array}{l}\text { Sistema não contempla } \\
\text { totalmente }\end{array}$ & Controle paralelo \\
\hline Pós-publicação & $\begin{array}{l}\text { Sistema não contempla } \\
\text { totalmente }\end{array}$ & Controle paralelo \\
\hline
\end{tabular}

Fonte: Elaborado pelos autores (2019)

\section{CONSIDERAÇÕES FINAIS}

Em uso na PUCPR há pouco tempo, o OJS é ainda um sistema relativamente novo para os usuários da instituição e, apesar de apresentar vantagens importantes, também apresenta desafios pontuais que devem ser solucionados.

Como exposto neste relato, as vantagens percebidas são substanciais, como a transparência do processo editorial, a melhora na comunicação com os autores, o maior controle da produção editorial, a melhora no sistema de metadados e a otimização dos tempos de produção. Essas vantagens eram esperadas e, conforme o uso do sistema pelos usuários for amadurecendo, espera-se que tais vantagens sejam ainda mais perceptíveis.

Em relação aos desafios, a percepção é de que a maioria deles é gerada pela falta de experiência dos usuários, pela sazonalidade de algumas operações ou pela ausência, no sistema, de métodos de controle específicos. Esses tipos de desafios também eram esperados. Para os primeiros dois tipos, a solução passa por treinamentos específicos, tutoriais acessíveis e validados e, por fim, pelo próprio uso, que devem gerar, em tempo, autonomia dos usuários. Segundo Eluan (2009, p. 103), "Os editores se envolvem com o processo de editoração de periódicos científicos eletrônicos", trabalhando nessa função por anos. Esse dado prevê que o uso das funcionalidades do sistema vá ser aprimorado com o tempo e treinamentos, pois a função de editor tende a ser estável dentro de um periódico.

Para o treinamento de usuários que não fazem parte da equipe da revista, é aconselhável que sejam dadas mais instruções via site das revistas ou através dos e-mails que o 
próprio sistema permite mandar. Esse método facilitaria a comunicação e possivelmente diminuiria as ocorrências de dúvidas entre esses usuários.

A respeito dos métodos de controle específico, especialmente na parte de edição de layout e pós-publicação, a criação de uma planilha tem se mostrado suficiente para controlar os processos. Assim, embora não seja possível mapear absolutamente todas as etapas do processo com apenas o OJS, a solução para estes desafios se mostra razoavelmente simples. Deve-se indicar ainda, aqui, que o controle paralelo já existia quando do sistema anterior em vigor na PUCPR para gerenciar periódicos, ou seja, não é uma exclusividade proveniente do uso do OJS.

No geral, levando em conta o processo de produção editorial dos periódicos da instituição aqui considerados, os desafios e vantagens do sistema e o tempo de adaptação dos usuários, avaliamos que o uso do OJS é benéfico e tem sido suficiente para a gestão dos periódicos da PUCPR apoiados pela PUCPRESS. Ressaltamos ainda que o presente relato de caso foi estruturado a partir das experiências e da percepção dos envolvidos na produção editorial de periódicos científicos e que o sistema está em uso há cerca de dois anos na instituição, sendo considerado, pelos usuários que têm contato com ele, um sistema ainda novo.

Para fins de pesquisa, sugere-se que seja feito um acompanhamento da situação dos periódicos e do desenvolvimento dos usuários do sistema a fim de verificar se o amadurecimento esperado está ocorrendo, como e em quanto tempo. Também se sugere que sejam feitas avaliações com os periódicos para confirmar, com dados decorrentes de um acompanhamento criterioso, se as percepções e experiências dos editores e das equipes se verificam nos periódicos geridos.

\title{
JOURNAL EDITORIAL PRODUCTION THROUGH OJS AT PUCPR: INITIAL CHALLENGES ON USING THE SYSTEM AND MANAGING JOURNALS
}

\begin{abstract}
This article aims to present the current status of the management of the editorial production of scientific journals at Pontificia Universidade Católica do Paraná (PUCPR), focusing on those to which PUCPRESS provides support. It shows the main advantages and challenges perceived during the use of Open Journal Systems (OJS). Among the advantages, there are the transparency of the editorial process and more visibility for articles using well-structured metadata. Among the challenges, we enlist those related to the experience of the user and the seasonal character of some operations, as well as minutiae of the editorial production that are not controlled enough inside the system. To bandle the challenges, strategies were created, convolving specific training and tutorials for the users of the system, especially editors and their journal's teams.
\end{abstract}

\section{Keywords}

Scientific journals. Editorial production. Open Journal Systems. Editorial management.

Artigo recebido em 15/01/2019 e aceito para publicação em 14/02/2019

\section{REFERÊNCIAS}

ALPERIN, Juan Pablo; STRANACK, Kevin; GARNETT, Alex. On the Peripheries of Scholarly Infrastructure: A look at the Journals Using Open Journal Systems. In: INTERNATIONAL CONFERENCE ON SCIENCE AND TECHNOLOGY INDICATORS，21., 2016,
Valência. Proceedings... Valência: Editorial Universitat Politècnica de València, 2016. p. 58-65. Disponível em: <http://ocs.editorial. upv.es/index.php/STI2016/STI2016/paper/ viewFile/4543/2327>. Acesso em: 22 dez. 2018.

BRASIL. Instituto Brasileiro de Informação em Ciência e Tecnologia (Ibict). Sistema Eletrônico 
de Editoração de Revistas. 2018. Disponível em: $<$ http://www.ibict.br/tecnologias-para-informacao/ seer>. Acesso em: 22 dez. 2018.

ELUAN, Andrenizia Aquino. Análise do uso da plataforma Open Journal System para o processo de editoração eletrônica: um estudo focado nos editores de periódicos científicos eletrônicos de acesso livre em Ciência da Informação e Biblioteconomia no Brasil. 2009. $133 \mathrm{f}$. Dissertação (Mestrado em Ciência da Informação) Universidade Federal de Santa Catarina, Florianópolis, 2009. Disponível em: <https://repositorio.ufsc.br/ bitstream/handle/123456789/92481/267849.pdf>. Acesso em: 23 dez. 2018.

FERREIRA, Ana Gabriela Clipes; CAREGNATO, Sônia Elisa. A editoração eletrônica de revistas científicas brasileiras: o uso de SEER/OJS. Transinformação, Campinas, v. 20, n. 2, p. 171-180, ago. 2008. Disponível em: <http://www.redalyc.org/ articulo.oa?id $=384334798005>$. Acesso em: $22 \mathrm{dez}$. 2018.

KEVIN. How many journals use OJS? Public Knowledge Project News. 2015. Disponível em: $\quad<$ https://pkp.sfu.ca/2015/10/01/how-manyjournals-use-ojs/>. Acesso em: $23 \mathrm{dez} .2018$.

PUBLIC KNOWLEDGE PROJECT (PKP). Portal PKP. 2014. Disponível em: <https://pkp.sfu.ca/>. Acesso em: 22 dez. 2018.

WILLINSKY, John. Open Journal Systems. Library Hi Tech, [s.1.], v. 23, n. 4, p.504-519, dez. 2005. Emerald. http://dx.doi.org/10.1108/07378830510636300.

*Versão revista e ampliada do Trabalho "A produção editorial de revistas científicas por meio do ojs na pucpr: desafios iniciais da utilização do sistema e da gestão de periódicos" apresentado no evento ABEC MEETING, 11-14, setembro, São Paulo, SP, 2018. 